\title{
UMA ANÁLISE DA EXPANSÃO DA PÓS-GRADUAÇÃO EM DIREITO NO \\ BRASIL - 1995/2020
}

Aldacy Rachid Coutinho ${ }^{1}$

\section{Introdução}

Datas comemorativas nos remetem, sempre, a um momento de análise para perscrutar o passado que hoje nos constitui, de tal sorte que, mediante um necessário balanço, se possa festejar os avanços ou eventualmente corrigir os desvios, apontando de todo modo para a construção de um mais profícuo futuro para a pós-graduação em Direito no Brasil. O pioneirismo da Faculdade de Direito do Largo de São Francisco, criada em 11 de agosto de 1827, acompanhado do Programa de Pós-graduação em Direito mais antigo do Brasil e que em 2021 completará meio século de atividades ininterruptas, testemunha a expansão da pós-graduação stricto sensu em Direito no país, sem percalços nas avaliações, nem capturas pela lógica mercantilista da educação ou ditames do mercado.

Se em 1827 a Faculdade de Direito da Universidade de São Paulo marcava sua presença ao lado da Faculdade de Direito de Olinda, atualmente desponta em excelência dentre 1.803 cursos de Direito. Tal constatação de expansão na graduação nos insta a perquirir e analisar, por dados e números, o crescimento quantitativo de cursos de mestrado e doutorado em Direito relativos aos anos 1995/2020, de sorte a aferir se compartilham dessa mesma realidade de expansão e/ou se estariam com ela relacionada.

Ensino, definitivamente, não é e nem deve ser tido como mercadoria; expressão da cidadania, consubstancia-se em direito fundamental inscrito na Constituição da República de 1988. Na economia capitalista de mercado não monopolista, a pretensa "coisificação" da educação superior em uma sociedade de massa, que se disfarça em sociedade de conhecimento, projeta todo discurso para um espaço de oferta/demanda pautado pela lógica dos custos e pela racionalidade da eficiência.

Vivencia-se desde muito uma crise de identidade, perceptível e acentuada pelas dificuldades dos incluídos, pressão e crítica dos não incluídos e desconhecimento dos não incluíveis no Sistema Nacional de Pós-graduação - SNPG, sob pressão de um crescimento desmesurado de Faculdades de Direito e da necessidade de qualificação - erroneamente confundida com a titulação - dos recursos humanos disponíveis.

Advogada. Mestre e Doutora. Professora titular de Direito do Trabalho da Universidade Federal do Paraná, aposentada. Professora do curso de mestrado acadêmico em Direito da Univel. 
Traduzindo em números, segundo a Ordem dos Advogados do Brasil, o número de advogados inscritos em novembro de 2020 supera o patamar de 1 milhão e duzentos mil. ${ }^{2}$

As instituições de ensino públicas não seguem e nem devem sucumbir à mesma lógica e assim resistem, não obstante enfrentem dificuldades de toda ordem, inclusive de recursos humanos e financiamento/fomento. Vêm se mantendo, com padrões de excelência, tanto na graduação quanto na pós-graduação, a exemplo da USP, concretizando o acesso a ensino público gratuito e de qualidade. Tradicionalmente a área do Direito, por seu comitê, composto de professores doutores pesquisadores e consultores ad hoc que colaboram temporária, voluntária e graciosamente como membros, procurou adotar uma política de expansão criteriosa, como já pontuava o professor Fernando Facury Scaff, "fortemente focada na qualidade da pesquisa, e muito mais centrada em uma desconcentração da pós-graduação dos grandes centros, do que na massificação do ensino pós-graduado em Direito ". ${ }^{3}$ E la nave và.

Expansão, sim. Também crescimento, é claro. Porém, desde que respeitado o inafastável comprometimento com a qualidade, mantido a "qualquer custo" e devidamente acompanhado de investimento. Reputa-se representativa a expansão na área do Direito nos últimos 35 anos em face das demandas apresentadas.

\section{Integrando o SNPG}

A pós-graduação se perfaz com a formação e o aperfeiçoamento de docentes e pesquisadores, no intercâmbio de conhecimento entre as distintas ciências e campos, por meio da produção intelectual. O Parecer Sucupira, ${ }^{4}$ conhecido pelo nome do relator na Câmara de Ensino Superior (C.E.Su) do então Conselho Federal de Educação, professor Newton Sucupira, elaborado em 3 de dezembro de 1965, por solicitação do à época Ministro da Educação e Cultura Flávio Suplicy de Lacerda, para regulamentar o

2 Ordem dos Advogados do Brasil. Total de advogados inscritos: 1.208.636. Disponível em: https://www. oab.org.br/institucionalconselhofederal/quadroadvogados. Acesso em: 22 nov. 2020; FUNDAÇÃO GETÚLIO VARGAS; ORDEM DOS ADVOGADOS DO BRASIL. Exame de ordem em números. v. 4, 2020. Disponível em: https://www.conjur.com.br/dl/exame-ordem-numeros-2020.pdf. Acesso em: 20 nov. 2020.

3 Documento de Área, Área de Direito, 2001-2003, setembro de 2004, Representante da Área do Direito junto a CAPES, professor Fernando Facury Scaff. COUTINHO, Aldacy Rachid. Expansão e investimento na Pós-graduação em Direito no Brasil - 1995/2005. Revista da Faculdade de Direito da Universidade Federal do Paraná, Curitiba, n. 45, p. 133, 2006. Disponível em: https://revistas.ufpr.br/direito/issue/ view/623. Acesso em: 20. nov. 2020.

4 Reforma universitária e consolidação do regulamento da pós-graduação. Parecer n. 977, de 03 de dezembro de 1965. InfoCapes-Boletim Informativo da CAPES. Brasília, out./dez.99, v. 7, n. 4, p. 37-51. Parecer CFE n 977/65, aprovado em 3 dez.1965 Revista Brasileira de Educação, n.30, Rio de Janeiro, set./dez.2005. Disponível em: https://www.scielo.br/scielo.php?script=sci_arttext\&pid=S1413-24782005000300014. Acesso em: 20 nov. 2020. 
artigo 69, letra "b", da Lei n. 4.024, de 20 de dezembro de 1961, dita Lei de Diretrizes e Bases da Educação, ${ }^{5}$ dá conta de uma longa trajetória da construção da pós-graduação no Brasil, que se confunde com a da pós-graduação da faculdade de Direito da USP. Ao precisar conceitos visando a implantação e desenvolvimento do regime de cursos de pós-graduação, acabou por fixar os pilares e estabelecer os marcos das políticas públicas que dimensionam a atuação do Estado até os nossos dias. Eis, diga-se desde logo, um dos poucos setores onde o país tem - e vem executando - políticas públicas com continuidade.

A pós-graduação se revelou, consoante ressaltado no parecer Sucupira, como a "conseqüência natural do extraordinário progresso do saber", inviável enquanto espaço de exclusividade da graduação que se volta sobretudo à preparação de profissionais. Projetou-se, então, a pós-graduação, para a formação de pesquisadores e docentes. Por conseguinte esclarece o parecerista: a pós-graduação sensu stricto se caracteriza fundamentalmente pela (a) natureza acadêmica e de pesquisa, permanecendo para o lato sensu a especialização prático-profissional; (b) confere grau acadêmico e não um mero certificado, tal qual ocorre nas especializações; (c) possui uma sistemática, formando estrato essencial e superior na hierarquia dos cursos dentro do complexo universitário, escalonada em dois níveis distintos ou ciclos, o Mestrado e o Doutorado, que apesar de hierarquizados são relativamente autônomos, porquanto um não é necessariamente a condição indispensável ao ingresso no curso seguinte.

No ápice, o Curso de Doutorado; salientando que pós-doutorado não é grau acadêmico, e por conseguinte, não se consubstancia em titulação a ser conferida. Imperioso notar que a preparação para o exercício do magistério superior é realizada tanto em cursos de Mestrado quanto de Doutorado acadêmicos ${ }^{6}$ e embora professor seja profissão (professor(a), além de dar aulas, ainda trabalha?), os cursos profissionais têm como objetivo precípuo a preparação para o mercado de trabalho. Segundo a Associação Nacional de Pós-graduandos:

O Mestrado Profissional é ideal para profissionais que querem continuar os estudos mas não desejam necessariamente dar aula no ensino superior ou ficar restrito a um laboratório. Além disso, é uma pós-graduação que

\footnotetext{
Art. 69. Nos estabelecimentos de ensino superior podem ser ministrados os seguintes cursos:

[...] b) de pós-graduação, abertos a matrícula de candidatos que hajam concluído o curso de graduação e obtido o respectivo diploma. Brasil. Lei 4.024, de 20 de dezembro de 1961. Fixa as diretrizes e bases da educação nacional. Disponível em: http://www.planalto.gov.br/ccivil_03/leis/14024.htm. Acesso em: 20 nov. 2020.

6 Art. 66. A preparação para o exercício do magistério superior far-se-á em nível de pós-graduação, prioritariamente em programas de mestrado e doutorado. Lei 9.394, de 20 de dezembro de 1996. LDB Lei de Diretrizes e Bases da Educação. Disponível em: http://www.planalto.gov.br/ccivil_03/leis/L9394. htm\#art92. Acesso em: 20 nov. 2020.
} 
vem sendo muito valorizada no mercado de trabalho. Isso porque o curso prepara mestres para atuar em diferentes áreas e não somente em contexto acadêmico.

O mestrado profissional é diferente do mestrado "tradicional". Apesar de manter a mesma estrutura de tempo, metodologia de pesquisa e avaliação, o mestrado profissional se difere do tradicional em sua abrangência e aplicação.

[...]

Os profissionais que cursam mestrado profissional não ficam restritos à atuação numa universidade. Do contrário, eles são estimulados a levar todo o conhecimento científico adquirido para o mercado, a fim de melhorar a qualidade de produtos, serviços e processos. ${ }^{7}$

Neste trilhar, a Fundação Coordenação de Aperfeiçoamento de Pessoal Superior (CAPES) tem a função de credenciar e avaliar para fins de manutenção do credenciamento os Cursos de Pós-graduação, acadêmicos ou profissionais, atuando ademais como agência pública de fomento da pesquisa (com bolsas somente para acadêmicos) a partir da edição de políticas públicas de pós-graduação. A CAPES, criada pelo Decreto n. 29.741, de 11 de julho de 1951, tem como objetivo "assegurar a existência de pessoal especializado em quantidade e qualidade suficientes para atender às necessidades dos empreendimentos públicos e privados que visam ao desenvolvimento do país”. Em 1981, pelo Decreto n. 86.791, passou a ser reconhecida como órgão responsável pela elaboração do Plano Nacional de Pós-graduação stricto sensu e agência executiva do então Ministério da Educação e Cultura, assumindo a função de elaborar, avaliar, acompanhar e coordenar as atividades da pós-graduação. Posteriormente foi transformada em Fundação, pela Lei n. 8.405, de 9 de janeiro de 1992.

Por certo que a Constituição da República de $1988^{8}$ assegura às Universidades $^{9}$ a autonomia como princípio, porém tal não significa estar à margem de diretrizes ${ }^{10}$ estabelecidas no legítimo interesse de toda a sociedade em prol de um padrão

7 Mestrado profissional como funciona? Associação nacional de pós-graduandos. 26fev.2019. Disponível em: http://www.anpg.org.br/26/02/2019/mestrado-profissional-como-funciona/?utm source=google\&utm_medium $=$ cpc\&utm_term $=$ anpg-cpc\&gclid=CjwKCAiA5IL-BRAzEiwA0lcWYj23Rj1aafGYwN0QczwU38bDCO3Y51ZF-SPOJpK1fbMHbcgkKfPaxoCyG0QAvD_BwE. Acesso em: 20 nov. 2020.

8 Constituição da República de 1988. Art. 207. As universidades gozam de autonomia didático-científica, administrativa e de gestão financeira e patrimonial, e obedecerão ao princípio da indissociabilidade entre ensino, pesquisa e extensão.

9 Quanto à organização acadêmica, as instituições do Sistema Federal de Ensino são classificadas em universidades, centros federais de educação tecnológica e centros universitários, faculdades integradas e de tecnologia e faculdades e institutos e escolas superiores.

10 Constituição da República de 1988. Art. 209. O ensino é livre à iniciativa privada, atendidas as seguintes condições: I - cumprimento das normas gerais da educação; II - autorização e avaliação de qualidade pelo 
mínimo de excelência. Autonomia, como é primário, não é aval à irrestrita liberdade de atuação e, portanto, vem delimitada pelo marco regulatório dentro do qual se pode até ter a possibilidade de fazer incidir a conveniência e oportunidade. Porém, não se coadune com a autonomia o arbítrio, com o qual se vê corriqueiramente confundido. Daí que a abertura e o funcionamento de cursos de pós-graduação stricto sensu dependem da prévia análise de um projeto que, obtendo parecer favorável ou não no Comitê da Área do Direito, deve ainda ser aprovado pelo Comitê Técnico Científico (CTC) na CAPES para, posteriormente, ser homologado pelo Conselho Nacional da Educação (CNE), vinculado ao Ministério da Educação.

O curso poderá iniciar suas atividades somente a partir da publicação da respectiva Portaria de reconhecimento no Diário Oficial da União, pelo que a lógica do mercado se submete aos ditames das políticas públicas. Somente programas que integrem o Sistema Nacional de Pós-graduação, pelo prévio reconhecimento, poderão emitir títulos com validade nacional, perdendo tal prerrogativa se na avaliação se comprovar a insuficiência dentro de um padrão mínimo de qualidade. No aspecto temporal, o critério de fixação da validade do título é dado pela data de ingresso do pós-graduando no curso, em necessidade de preservação da aparência, boa-fé e segurança jurídicas, pelo que a saída de um programa do Sistema Nacional de Pós-graduação não impede de imediato a outorga do grau acadêmico, mas restringe a possibilidade àqueles que já integravam o corpo discente quando da avaliação negativa.

Como a autorização e o reconhecimento dos cursos, assim também o credenciamento das instituições tem prazo limitado e a renovação periódica, sendo procedida após regular processo de avaliação. ${ }^{11}$ A CAPES mantém registros dos cursos desde 1976, quando a avaliação de mérito de todos os que integram o Sistema Nacional de Pós-graduação (SNPG) teve seu início:

Inicialmente, tais registros restringiam-se aos dados básicos sobre a constituição do PPG, como seu ano de início e os respectivos níveis de cursos (mestrado e/ou doutorado) nele existentes, bem como as informações sobre os totais de discentes por situação de matrícula e de totais de docentes vinculados ao programa. A coleta era realizada por meio do envio dos dados agregados, em tabelas, utilizando formulários de papel. No ano de início da avaliação, a pós-graduação stricto sensu brasileira contava com 181 cursos de mestrado e 518 de doutorado, distribuídos em 524 programas. $^{12}$

Poder Público.

11 Lei de Diretrizes e Bases da Educação Superior-LDB. Art. 46. Lei 9.394, de 20 de dezembro de 1996.

12 Disponível em: https://metadados.capes.gov.br/index.php/catalog/165. Acesso em: 16 nov. 2020. 
O datacapes como sistema anual de coleta de dados e informações em autolançamento se manteve entre os anos 1988 e 1995. A avaliação era procedida a partir das informações prestadas diretamente pelos Programas através de um relatório anual datacapes, preenchido ${ }^{13}$ on-line com a chancela da respectiva pró-reitoria de pósgraduação de cada instituição, bem como diante de informações prestadas através do cadastro discente e banco nacional de teses e dissertações enviadas em pdf a serem disponibilizadas para acesso irrestrito ao público. Os avaliadores, oriundos da comunidade científica, exercendo função pública não remunerada, ao avaliar os pares garantem um tratamento não tecnicista no manejo dos dados, preservando as especificidades de cada área.

O Coleta de Dados, de 1996 a 2002, representou um aprimoramento decorrente do uso da tecnologia para formação de um banco de dados, informando os programas e cursos o fluxo discente e docente e os autores da produção intelectual. No ano de 2003 a identificação individual de discentes e docentes passa a ser pelo número do Cadastro de Pessoa Física (CPF) obtido junto à Receita do Brasil. Somente em 2004, o Sistema Nacional de Pós-graduação (SNPG) conta com cursos de mestrado profissional, ao lado de mestrados e doutorados acadêmicos.

Em 2013 o Coleta de Dados deixa de ser informado a partir de um aplicativo instalado no sistema de computadores de programas e/ou cursos; o preenchimento ocorre diretamente na Plataforma Sucupira, aberta em fluxo contínuo.

a Plataforma, as informações podem sofrer atualizações recorrentes, mesmo aquelas de anos de referência anteriores. No entanto, os dados que são considerados para os fins de avaliação, são obtidos a partir daqueles existentes em um momento específico, cujos registros ficam congelados. Eles configuram uma imagem da estrutura e constituição do PPG. Para garantir que tal imagem represente fidedignamente o PPG, ela deve ser homologada tanto pelo (a) Coordenador (a) responsável pelo Programa de Pós-Graduação, quanto pelo (a) PróReitor (a) de Pesquisa e Pós-Graduação (ou Órgão equivalente) da Instituição de Ensino à qual o Programa de Pós-Graduação está vinculado. Por motivos diversos: como falhas de sistema ou nova oportunidade para envio dos dados do Coleta, por exemplo, os Programas de PósGraduação podem retificar as informações declaradas em momento posterior predefinido. ${ }^{14}$

13 Até 2006, vinha sendo preenchido off line e encaminhado por suas respectivas Pró-Reitorias de Pósgraduação à CAPES; após, o cadastro discente e envio de trabalhos de conclusão em pdf para o banco de teses e dissertações permanece aberto todo o ano.

14 Disponível em: https://metadados.capes.gov.br/index.php/catalog/165. Acesso em: 16 nov. 2020. 
Para cada um dos envios é gerada uma imagem dos dados declarados e homologados. Caso um determinado PPG tenha múltiplas imagens encaminhadas e homologadas, apenas a última é considerada para os fins de avaliação.

As avaliações contínuas a que todos os Programas reconhecidos se submetem certificam os padrões de excelência nos estudos e pesquisa e não parâmetros de mercado, pela oferta/demanda. A criação da sistemática de avaliação continuada pela CAPES está em vigência desde 1999. Apenas a título de esclarecimento, até 1998 (1996-1998) a avaliação era bianual, sendo que desde 1996 a classificação deixa de ser procedida por letras (A, B, C, D e E), sendo parametrizada por meio dos números 1(um) a 7(sete). A primeira avaliação trienal ocorreu a partir dos anos 1998-2000, sendo que desde 2013-2017 passa a ser quadrienal e devem servir de indicativos tanto para o planejamento e ações dos próprios Programas (com vistas a eventuais mudanças e ajustes procedidos para seu fortalecimento diante de pontos fracos apontados), quanto para a Comissão de Área que, no último ano do quadriênio triênio, procede à verificação do desempenho com base nos critérios previamente estabelecidos e publicizados, atribuindo-lhes uma nota.

Em uma escala de conceitos de 1 (um) a 7 (sete), em sentido crescente de qualidade, o credenciamento e manutenção no Sistema Nacional de Pós-graduação do Programa em que dependem de nota mínima 3 (três), o que lhe permite a emissão de um título com validade nacional, as notas 6 (seis) e 7 (sete) são atribuídas a Programas que contam com cursos de Mestrado e Doutorado em padrões de excelência, situação em que se encontra, tradicionalmente a USP por seu Programa de Pós-graduação em Direito.

O perfil de excelência expressa o atendimento das definições e peculiaridades estabelecidas em cada Área, servindo de parâmetro para revelar um padrão acadêmico de inserção internacional.

O programa de Pós-graduação da Faculdade de Direito da Universidade de São Paulo foi criado no ano de 1970, ${ }^{15}$ pelo então Reitor, professor Miguel Reale. No período analisado, isto é, nos últimos 35 anos, se manteve com avaliações que atestaram a sua excelência na área do Direito, com expressão de nota 6.

\section{Um olhar na Expansão ${ }^{16}$}

A análise do período 1996-2020 demonstra que a expansão foi contínua e significativa, tanto para cursos de mestrado quanto para doutorado (tabela 1). O

\footnotetext{
5 Portaria GR 1211, de 25 de junho de 1970.

16 Todos os dados da expansão foram obtidos e fornecidos pela CAPES, estando disponíveis nas estatísticas divulgadas no sítio www.capes.gov.br.
} 
crescimento foi maior para cursos de doutorado, que eram 4 no ano de 1996, passando a contar com 54 no ano de 2020, isto é, um aumento de 1250\%. A ampliação de cursos de mestrado acadêmico na área do Direito foi menor, passando de 18 cursos em 1996 a 109 em 2020, ou seja, um incremento acumulado no período de 506\%. Em 1996 tínhamos para cada curso de doutorado o equivalente a 4,5 cursos de mestrado; a proporção vem reduzida e passa em 2020 a ser 2 cursos de mestrado para cada curso de doutorado oferecidos. Na análise da expansão desponta o ano de 1998 por conta de um incremento muito significativo de cursos de doutorado, identificado em $120 \%$, o que não se verifica nos cursos de mestrado ou mesmo de doutorado nos outros anos, já que a expansão nunca ultrapassara a $31 \%$.

Tabela 1 - Expansão de cursos de mestrado e doutorado acadêmicos em Direito 1996/2020

\begin{tabular}{|c|c|c|c|c|}
\hline Ano & $\begin{array}{l}\text { Cursos de } \\
\text { doutorado } \\
\text { acadêmico }\end{array}$ & Expansão anual & $\begin{array}{l}\text { Cursos de } \\
\text { mestrado } \\
\text { acadêmico }\end{array}$ & Expansão anual \\
\hline & & $\begin{array}{c}1250 \% \\
\text { acumulado }\end{array}$ & & $\begin{array}{c}506 \% \\
\text { acumulado }\end{array}$ \\
\hline 2020 & 54 & $20 \%$ & 109 & $3 \%$ \\
\hline 2019 & 45 & $18 \%$ & 106 & $7 \%$ \\
\hline 2018 & 38 & $0 \%$ & 99 & $0 \%$ \\
\hline 2017 & 38 & $6 \%$ & 99 & $4 \%$ \\
\hline 2016 & 36 & $6 \%$ & 95 & $8 \%$ \\
\hline 2015 & 34 & $3 \%$ & 88 & $2 \%$ \\
\hline 2014 & 33 & $0 \%$ & 86 & $12 \%$ \\
\hline 2013 & 33 & $3 \%$ & 77 & $1 \%$ \\
\hline 2012 & 32 & $3 \%$ & 76 & $13 \%$ \\
\hline 2011 & 31 & $19 \%$ & 67 & $10 \%$ \\
\hline 2010 & 26 & $4 \%$ & 61 & $-6 \%$ \\
\hline 2009 & 25 & $14 \%$ & 65 & $7 \%$ \\
\hline 2008 & 22 & $5 \%$ & 61 & $3 \%$ \\
\hline 2007 & 21 & $17 \%$ & 59 & $2 \%$ \\
\hline 2006 & 18 & $20 \%$ & 58 & $9 \%$ \\
\hline 2005 & 15 & $0 \%$ & 53 & $10 \%$ \\
\hline 2004 & 15 & $7 \%$ & 48 & $7 \%$ \\
\hline 2003 & 14 & $7 \%$ & 45 & $7 \%$ \\
\hline 2002 & 14 & $0 \%$ & 42 & $14 \%$ \\
\hline
\end{tabular}




\begin{tabular}{|c|c|c|c|c|}
\hline 2001 & 14 & $27 \%$ & 37 & $9 \%$ \\
\hline 2000 & 11 & $0 \%$ & 34 & $31 \%$ \\
\hline 1999 & 11 & $0 \%$ & 26 & $13 \%$ \\
\hline 1998 & 11 & $120 \%$ & 23 & $15 \%$ \\
\hline 1997 & 5 & $25 \%$ & 20 & $11 \%$ \\
\hline 1996 & 4 & $\mathrm{n} / \mathrm{a}$ & 18 & $\mathrm{n} / \mathrm{a}$ \\
\hline
\end{tabular}

Verifica-se que o crescimento do número de cursos de Mestrado e Doutorado, ano a ano, não foi linear, nem seguiram uma mesma tendência, sendo por vezes até negativo como em 2010 para cursos de mestrado, o que revela à saciedade que a expansão não fora resultado de uma específica política pública de algum governo ou fomento, de algum critério ou decisão da área do Direito, quer para ampliar as públicas em detrimento das privadas - ou vice-versa -, quer para aumentar prioritariamente a oferta de cursos de mestrado ou de doutorado em uma específica região ou estadomembro. Talvez, mas está fora do objeto do presente estudo, possa ter tido o Comitê de Área algum impacto na limitação da expansão.

Impõe-se precisar que para analisar o quantitativo de cursos de mestrado, acadêmico e profissional e de doutorado em Direito não foram levados em conta os dados de programas. Isto porquanto algumas peculiaridades e especificidades poderiam dificultar as conclusões. Apenas a título de exemplo, indica-se a situação da Universidade Federal Fluminense (UFF) que oferta dois cursos de pós-graduação que não se integram em um Programa: um curso de doutorado em Direito, instituições e negócios, com início em 2016 e um curso de mestrado em Direito Constitucional, com início em 201, ambos com nota 4 e a situação da Escola de Direito de São Paulo (FGV- Direito SP) mantêm dois Programas, um com um curso de mestrado profissional que se iniciou em 2013 e não se integrou ao Programa que já contava com um curso de mestrado acadêmico (2008) e outro de doutorado (2018).

A hipótese de que a expansão dos cursos de mestrado e doutorado acadêmicos na área de Direito foi mais intensa porquanto revelaria o impacto da pressão exercida pela ampliação desmesurada da graduação não resulta como hipótese a partir dos dados coletados (tabelas 1 e 2). Não se há de rechaçar, contudo, a crítica contundente em torno do número expressivo de cursos de graduação em Direito. Em novembro de 2020 contabilizamos no Brasil 1803 cursos de Direito, que disponibilizam 341.177 vagas anuais. Em 2017 eram 1203, o que representa um aumento de 600 cursos novos nos últimos 3 anos. ${ }^{17}$

\footnotetext{
17 Dados obtidos em consulta no E-mec. Disponível em: https://emec.mec.gov.br/. Acesso em: 22 nov. 2020. 
Tabela 2 - Oferta de cursos de graduação em Direito no Brasil

$1995 / 2017$
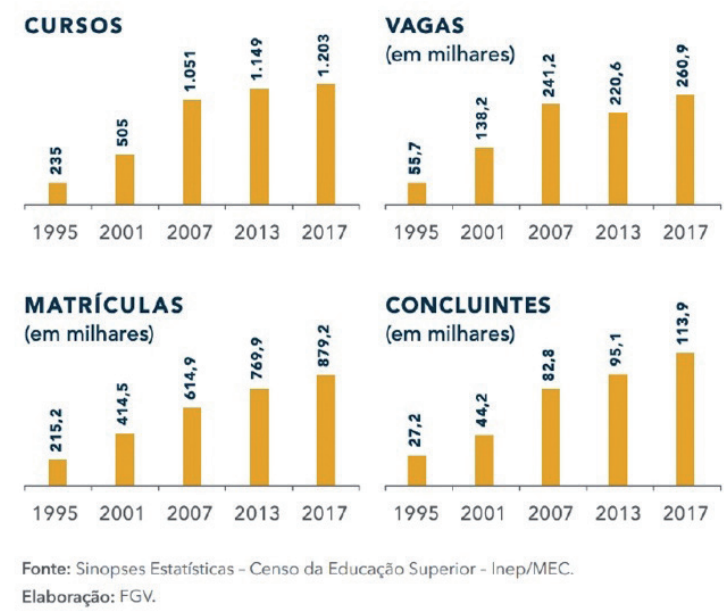

Segundo ponderou o Presidente do Conselho Federal da Ordem dos Advogados do Brasil em 2014, "nenhum país do mundo possui tantos cursos de Direito quanto o Brasil". ${ }^{18}$ Todavia, no período de 2001 a 2020 (tabela 3) a análise comparativa do incremento de cursos de graduação em Direito e de cursos de pós-graduação stricto sensu (mestrado e doutorado) revelam que a expansão em relação aos cursos de graduação (257\%) não foi tanto mais intensa do que a da pós-graduação em cursos de doutorado $(286 \%)$ e no mestrado (195\%).

Tabela 3 - Expansão comparativa de cursos de graduação e pós-graduação em Direito 2001/2020

\begin{tabular}{|c|c|c|c|c|c|c|}
\hline Ano & $\begin{array}{c}\text { Faculdades } \\
\text { de Direito }\end{array}$ & Expansão & $\begin{array}{c}\text { Cursos de } \\
\text { Mestrado } \\
\text { acadêmico }\end{array}$ & Expansão & $\begin{array}{c}\text { Cursos de } \\
\text { doutorado }\end{array}$ & Expansão \\
\hline acumulado & $\mathbf{1 2 9 8}$ & $\mathbf{2 5 7 \%}$ & $\mathbf{7 2}$ & $\mathbf{1 9 5 \%}$ & $\mathbf{4 0}$ & $\mathbf{2 8 6 \%}$ \\
\hline 2020 & 1803 & $50 \%$ & 109 & $10 \%$ & 54 & $42 \%$ \\
\hline 2017 & 1203 & $5 \%$ & 99 & $29 \%$ & 38 & $15 \%$ \\
\hline 2013 & 1149 & $9 \%$ & 77 & $31 \%$ & 33 & $57 \%$ \\
\hline 2007 & 1051 & $108 \%$ & 59 & $59 \%$ & 21 & $50 \%$ \\
\hline 2001 & 505 & $\mathrm{n} / \mathrm{a}$ & 37 & $\mathrm{n} / \mathrm{a}$ & 14 & $\mathrm{n} / \mathrm{a}$ \\
\hline
\end{tabular}

Fonte: a autora/ CAPES e FGV 2020

18 Congresso em foco. OAB critica "recorde" do Brasil em cursos de Direito. 22 jan. 2014. Disponível em: https:/congressoemfoco.uol.com.br/especial/noticias/brasil-recordista-de-cursos-de-direito-no-mundo/. Acesso em: 20 nov. 2020. 
Tal conclusão não desconsidera, entretanto, e demanda nova pesquisa em torno da pressão eventualmente exercida pelos cursos de graduação para atingirem a meta estabelecida pela Lei de Diretrizes e Bases da Educação, que é a lei orgânica da educação brasileira, quanto ao percentual de $1 / 3$ de professores titulados mestres ou doutores ${ }^{19}$ ministrando aulas na graduação.

\section{Mestrado profissional}

A expansão mais ampla ocorreu nos cursos de mestrado profissional. O parecer Sucupira já previa a possibilidade de "cursos profissionalizantes". Até a edição da Portaria n. 47, de 1995, não havia regulamentação, nem tinham sido fixados os parâmetros para avaliação, o que denota, de uma parte, a inexistência de interesse para fomentar tais cursos e, de outra, ausência de interesse na oferta.

Ao passo que o Sistema Nacional de Pós-graduação contava com curso de mestrado profissional desde 2004, a área do Direito, tradicionalmente refratária à oferta de cursos de pós-graduação strictu sensu profissionais, ofertou seu primeiro curso apenas no ano de 2013 - oferecido pela FGV-Direito, recomendado em 24 de maio de 2021. E somente dois anos após, já em 2015, após recomendação datada de 12 de dezembro de 2014, a Unisinos e a Unifor passaram igualmente a ofertar, para além do mestrado acadêmico que mantinham, também mestrado profissional. Atualmente a área contabiliza um total de 22 cursos de mestrado profissional (tabela 4).

Tabela 4 - Cursos de mestrado profissionais em Direito no Brasil 2012-2020

\begin{tabular}{|l|l|c|c|c|c|c|}
\hline \multicolumn{1}{|c|}{ Curso } & \multicolumn{1}{|c|}{ Instituição de ensino } & $\begin{array}{c}\text { Início das } \\
\text { atividades } \\
\text { Recomendação } \\
\text { Mestrado } \\
\text { profissional }\end{array}$ & $\begin{array}{c}\text { Oferta } \\
\text { Mestrado } \\
\text { acadêmico }\end{array}$ & $\begin{array}{l}\text { Público ou } \\
\text { Privada }\end{array}$ & Estado \\
\hline $\begin{array}{l}\text { Direito e } \\
\text { desenvolvimento }\end{array}$ & $\begin{array}{l}\text { Escola de Direito de São Paulo } \\
\text { (FGV Direito SP) }\end{array}$ & 2013 & $24 / 05 / 2012$ & MA & privada & SP \\
\hline $\begin{array}{l}\text { Direito da empresa } \\
\text { e dos negócios }\end{array}$ & $\begin{array}{l}\text { Universidade do Vale do Rio } \\
\text { dos Sinos (UNISINOS) }\end{array}$ & 2015 & $12 / 12 / 2014$ & MA & privada & RS \\
\hline $\begin{array}{l}\text { Direito e Gestão de } \\
\text { Conflitos }\end{array}$ & $\begin{array}{l}\text { Universidade de Fortaleza } \\
\text { (UNIFOR) }\end{array}$ & 2015 & $12 / 12 / 2014$ & MA & privada & CE \\
\hline $\begin{array}{l}\text { Direito e acesso à } \\
\text { justiça }\end{array}$ & $\begin{array}{l}\text { Universidade Federal de Santa } \\
\text { Catarina (UFSC) }\end{array}$ & 2016 & $26 / 03 / 2015$ & MA & pública & SC \\
\hline $\begin{array}{l}\text { Direito e políticas } \\
\text { públicas }\end{array}$ & $\begin{array}{l}\text { Universidade Federal de Goiás } \\
\text { (UFG) }\end{array}$ & 2017 & $16 / 12 / 2016$ & MA & pública & GO \\
\hline
\end{tabular}

19 Art. 52, inciso II, da Lei 9.394, de 20 de dezembro de 1996. Lei de Diretrizes e Bases da Educação - LDB. Disponível em: http://www.planalto.gov.br/ccivil_03/leis/L9394.htm\#art92. Acesso em: 20 nov. 2020. 


\begin{tabular}{|c|c|c|c|c|c|c|}
\hline $\begin{array}{l}\text { Direito das } \\
\text { migrações } \\
\text { transnacionais }\end{array}$ & $\begin{array}{l}\text { Universidade do Vale do Itajaí } \\
\text { (UNIVALI) e Università degli } \\
\text { Studi di Perugia }\end{array}$ & 2018 & $16 / 12 / 2016$ & MA & privada & SC \\
\hline $\begin{array}{l}\text { Mestrado } \\
\text { profissional em } \\
\text { direito tributário } \\
\text { internacional }\end{array}$ & $\begin{array}{l}\text { Instituto Brasileiro de Direito } \\
\text { Tributário (IBDT) }\end{array}$ & 2017 & $16 / 12 / 2016$ & & privada & SP \\
\hline $\begin{array}{l}\text { Direitos sociais } \\
\text { e processos } \\
\text { reivindicatórios }\end{array}$ & $\begin{array}{l}\text { Centro Universitário do } \\
\text { Instituto de Educação Superior } \\
\text { de Brasília (IESB) }\end{array}$ & 2018 & $29 / 03 / 2017$ & & privada & DF \\
\hline $\begin{array}{l}\text { Direito, tecnologia } \\
\text { e desenvolvimento }\end{array}$ & Universidade Positivo (UP) & 2019 & $06 / 12 / 2018$ & & privada & PR \\
\hline $\begin{array}{l}\text { Direito econômico } \\
\text { e desenvolvimento }\end{array}$ & $\begin{array}{l}\text { Instituto brasiliense de direito } \\
\text { público (IDP) }\end{array}$ & 2019 & $06 / 12 / 2018$ & MA & privada & DF \\
\hline $\begin{array}{l}\text { Direito, regulação e } \\
\text { políticas públicas }\end{array}$ & Universidade de Brasília (UNB & 2019 & $06 / 12 / 2018$ & MA & publica & DF \\
\hline $\begin{array}{l}\text { Direito e gestão de } \\
\text { conflitos }\end{array}$ & $\begin{array}{l}\text { Universidade de Araraquara } \\
\text { (UNIARA) }\end{array}$ & 2019 & $06 / 12 / 2018$ & & privada & SP \\
\hline $\begin{array}{l}\text { Direito civil } \\
\text { contemporâneo e } \\
\text { prática jurídica }\end{array}$ & $\begin{array}{l}\text { Pontifícia Universidade } \\
\text { Católica do Rio de Janeiro } \\
\text { (PUC-RIO) }\end{array}$ & 2020 & $29 / 05 / 2019$ & MA & privada & RJ \\
\hline $\begin{array}{l}\text { Direito do } \\
\text { agronegócio e } \\
\text { desenvolvimento }\end{array}$ & $\begin{array}{l}\text { Universidade de Rio Verde } \\
\text { (UNIRV) }\end{array}$ & 2020 & $13 / 05 / 2020$ & & privada & GO \\
\hline $\begin{array}{l}\text { Direito e afirmação } \\
\text { de vulneráveis }\end{array}$ & $\begin{array}{l}\text { Universidade Ceuma } \\
\text { (UNICEUMA) }\end{array}$ & 2020 & $13 / 05 / 2020$ & & privada & MA \\
\hline $\begin{array}{l}\text { Direito e Poder } \\
\text { Judiciário }\end{array}$ & $\begin{array}{l}\text { Escola Nacional de Formação } \\
\text { e aperfeiçoamento de } \\
\text { magistrados Ministro Sálvio de } \\
\text { Figueiredo Teixeira (ENFAM) }\end{array}$ & 2020 & $15 / 05 / 2020$ & & privada & DF \\
\hline $\begin{array}{l}\text { Direito, sociedade } \\
\text { e tecnologias }\end{array}$ & Faculdades Londrina (FL) & 2020 & $15 / 05 / 2020$ & & privada & PR \\
\hline $\begin{array}{l}\text { Direito, mercado, } \\
\text { compliance e } \\
\text { segurança humana }\end{array}$ & Faculdade CERS (CERS) & 2020 & $15 / 05 / 2020$ & & privada & PE \\
\hline $\begin{array}{l}\text { Direito e } \\
\text { desenvolvimento } \\
\text { sustentável }\end{array}$ & $\begin{array}{l}\text { Centro universitário FACVEST } \\
\text { (UNIFACVEST) }\end{array}$ & 2020 & $15 / 05 / 2020$ & & privada & SC \\
\hline Direito & $\begin{array}{l}\text { Universidade estadual de } \\
\text { Ponta Grossa (UEPG) }\end{array}$ & Início - s/d & $15 / 05 / 2020$ & & $\begin{array}{l}\text { pública } \\
\text { estadual }\end{array}$ & PR \\
\hline $\begin{array}{l}\text { Direito, Justiça } \\
\text { e impactos na } \\
\text { economia }\end{array}$ & $\begin{array}{l}\text { Centro de estudos de direito } \\
\text { econômico e social (CEDES) }\end{array}$ & 2020 & $15 / 05 / 2020$ & & privada & SP \\
\hline $\begin{array}{l}\text { Direito e } \\
\text { desenvolvimento } \\
\text { na Amazônia }\end{array}$ & $\begin{array}{l}\text { Universidade Federal do Pará } \\
\text { (UFPA) }\end{array}$ & 2020 & $15 / 05 / 2020$ & MA & $\begin{array}{l}\text { pública } \\
\text { federal }\end{array}$ & PA \\
\hline
\end{tabular}

Fonte: CAPES 
Até o ano de 2015 as ofertas eram exclusividades de instituições privadas, mas naquele ano um curso de mestrado profissional em Direito e acesso à justiça obteve recomendação, em 26 de março de 2015, após apresentação de proposta pela Universidade Federal de Santa Catarina, com início das atividades em 2016. Naquele ano, em 16 de dezembro de 2016, outros três cursos foram aprovados, sendo mais um em universidade pública: Universidade Federal de Goiás; um em rede com uma instituição de ensino estrangeira, a Universidade do Vale do Itajaí (UNIVALI) e Università degli studi di Perugia, Itália; e outro por uma instituição que não oferece curso de graduação em Direito, o Instituto Brasileiro de Direito Tributário (IBDT).

Dentre os cursos de mestrado profissionais, 12 instituições de ensino superior adotaram o mestrado profissional como sua única opção (em detrimento do acadêmico); é o caso do Centro de Estudos de Direito Econômico e Social (CEDES), Universidade Estadual de Ponta Grossa (UEPG), Centro universitário Facvest (UNIFACVEST), Faculdades de Londrina (FL), Escola de Formação e Aperfeiçoamento de magistrados Ministro Sálvio de Figueiredo Teixeira (ENFAM), Universidade Ceuma (UNICEUMA), Universidade de Rio Verde (UNIRV), Universidade de Araraquara (UNIARA), Universidade Positivo (UP), Centro Universitário de Educação Superior de Brasilia (IESB), Instituto Brasileiro de Direito Tributário (IBDT).

Constata-se que a expansão vem sendo uma constante desde o primeiro curso de mestrado profissionais até ano de 2020, sendo que apenas no ano de 2013 nenhum novo curso de mestrado profissional fora recomendado, demonstrando que a área não mais manifesta resistência. Entretanto, merece particular destaque o fato de que o ano de 2020 testemunha uma explosão de cursos, sobretudo por instituições de ensino que não ofertam mestrados acadêmicos, talvez como a expressão de uma demanda de mercado, que privilegia a atuação profissional geral em detrimento da pesquisa e docência que é próprio e distintivo do mestrado acadêmico. A constatação é corroborada pelas áreas de concentração: dos 22 cursos de mestrado profissional, 6 tratam de desenvolvimento, 5 de solução de controvérsias, 3 de empresa e mercado, 1 de Direito Tributário, 1 de tecnologias e apenas 5 de direitos sociais, políticas públicas ou de afirmação ou 1 simplesmente direito (tabela 4).

$\mathrm{O}$ ano de 2020 consolida um crescimento de $2.100 \%$ desde o primeiro curso de mestrado profissional aprovado em 2012; os 9 novos cursos que ingressaram neste último ano representam, isoladamente, $40,91 \%$ da totalidade dos mestrados profissionais. No ano anterior (2019), por exemplo, somente um novo curso de mestrado profissional passou a integrar o Sistema Nacional de Pós-graduação. Na esteira da Portaria n. 389, de 
23 de março de 2017, que autorizou a criação doutorados profissionais, surge o primeiro doutorado profissional em 2018 e nenhum na área do Direito até $2020 .^{20}$

A disparidade regional e concentração no sul e sudeste é uma mesma realidade em se tratando de pós-graduação (cursos de doutorado e mestrados acadêmicos) e nos cursos de graduação (tabelas 4,5 e 6 ).

Tabela 5 - Distribuição de cursos de mestrado profissionais em Direito por região no Brasil

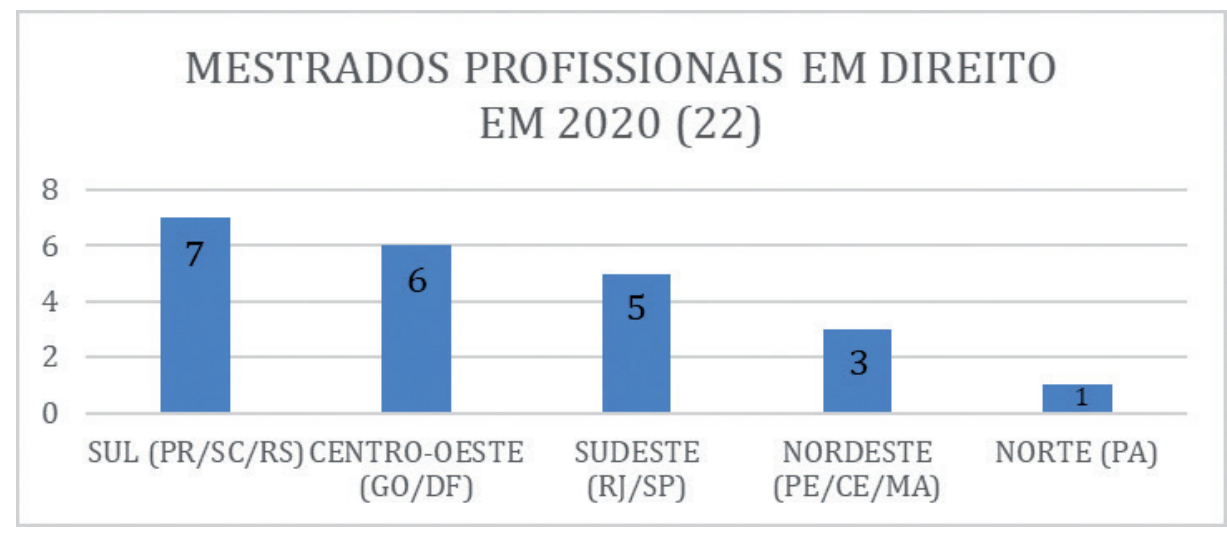

Fonte: a autora / CAPES 2020

Tabela 6 - Distribuição de cursos de graduação em Direito por região no Brasil

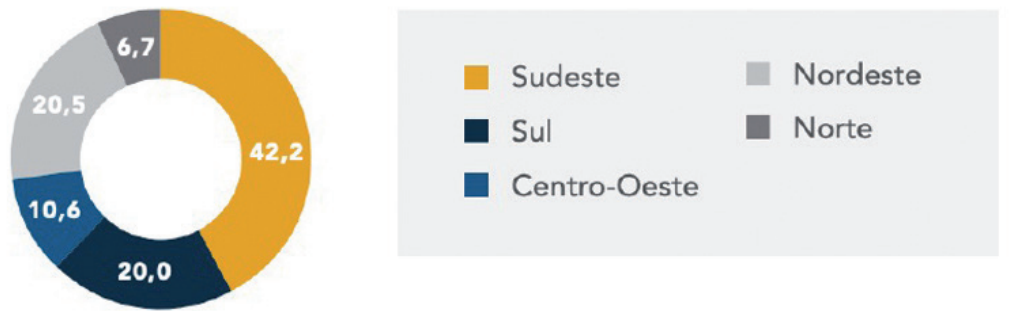

Fonte: Sinopses Estatísticas - Censo da Educaçăo Superior - Inep/MEC.

Elaboração: FGV.

20 SERVA, Fernanda Mesquita; CALDERÓN, Adolfo Ignacio; DIAS, Jefferson Aparecido. Doutorado profissional em Direito: tendências em universidades com melhor desempenho em rankings acadêmicos internacionais. Revista Brasileira de Pós-graduação, Brasília, v. 14, 19 out. 2017. Disponível em: http:// ojs.rbpg.capes.gov.br/index.php/rbpg/article/view/1425/pdf. Acesso em: 20. nov. 2020. 
A par da impactante expansão dos cursos de mestrado profissional, a distribuição dos cursos por região demonstra que mais da metade, ou seja, $54,5 \%$ dos cursos, é ofertado nas regiões sul e sudeste; apenas 1 curso é oferecido na região norte do Brasil, acirrando ainda mais o desequilíbrio no acesso.

\section{5. À̀ guisa de conclusão}

As políticas públicas estabelecidas pela Coordenação de Aperfeiçoamento de Pessoal de Nível Superior - CAPES nas últimas décadas primaram pela qualidade dos cursos de pós-graduação em detrimento da quantidade, na tentativa de preservar o sistema nacional de pós-graduação da pressão pela ampliação como decorrente da mercantilização da educação. Todavia, não impede, não obstante não fomente, a expansão numérica de cursos.

A análise da expansão quantitativa dos cursos de mestrado e doutorado acadêmicos e de mestrado profissional em Direito no Brasil nos anos 1995 a 2020, por meio de dados fornecidos pela Coordenação de Aperfeiçoamento de Pessoal de Nível Superior - CAPES, Ordem dos advogados do Brasil e Ministério da Educação, não conduz à conclusão no sentido de que tenha alguma relação necessária com o aumento expressivo de cursos de graduação e respectivas vagas ofertadas.

Ditames de mercado, com a perspectiva de transferência de conhecimento da universidade para o mercado de trabalho com vistas a incrementar o nível de qualificação profissional, testemunha o mais impactante crescimento em percentual verificado, que ocorreu nos cursos de mestrado profissional. $\mathrm{O}$ incremento mais recente na oferta de cursos de mestrado profissional na área do Direito, que mantém a mesma disparidade regional verificada nos cursos de graduação, demonstra como a pós-graduação é suscetível à demanda de mercado; aponta, ainda, para a superação de uma posição de relutância no tocante a esta modalidade. A oferta de cursos de mestrado profissional por instituições públicas embora seja uma posição favorável e suscetível à demanda de mercado, abre a possibilidade de maior acessibilidade a pós-graduandos ante a gratuidade da educação pública. 